\title{
The prone position must accommodate changes in IAP in traumatic brain injury patients
}

\author{
Wojciech Dabrowski ${ }^{i^{*}}$, Dorota Siwicka-Gieroba ${ }^{1}$, Chiara Robba², Rafael Badenes ${ }^{3}$ and \\ Manu L. N. G. Malbrain ${ }^{1,4,5}$
}

Dear Editor,

Recently, Bernon et al. evaluated in a retrospective study the safety and efficacy of prone position (PP) in patients treated for traumatic brain injury (TBI) and moderateto-severe acute respiratory distress syndrome (ARDS) [1]. They analyzed changes in $\mathrm{P}_{\mathrm{a}} \mathrm{O}_{2} / \mathrm{FiO}_{2}$ and intracranial pressure in 10 patients during PP. Although $\mathrm{PaO}_{2} /$ $\mathrm{FiO}_{2}$ improved, PP was discontinued due to a raised intracranial pressure (ICP) in 50\% of patients. Additionally, they found that all patients with ICP $>17.5 \mathrm{mmHg}$ and $28 \%$ of patients with ICP $<17.5 \mathrm{mmHg}$ prior PP had intracranial hypertension ( $\mathrm{ICH}$, defined as one or more ICP elevations $>25 \mathrm{mmHg}$ ) following PP. They concluded that monitoring of the brain compliance, ICP and the tolerance to venous return obstruction (Queckenstedt's maneuver) could be useful before decision of PP.

Severe ARDS makes the ventilator management of patients with TBI even more challenging. The European Society of Intensive Care Medicine strongly recommends to consider PP in patients with concomitant ARDS and TBI, if ICP is stable [2]. When PP is necessary, clinicians suggest to strictly monitor ICP, possibly with a multimodal neuromonitoring approach $[1,3]$ to early and promptly treat neurological complications. However, PP may increase intracranial pressure (ICP) via a reduction of blood outflow from the brain.

Several factors may impair venous outflow from the brain, and elevated intra-abdominal pressure (IAP) is one of them. Significant increase in IAP closely corresponds to an increase in central venous pressure, jugular venous bulb pressure and low jugular venous bulb saturation in critically ill patients [4]. It was documented that increased IAP played an important role in developing intracranial complications during neurosurgical procedures in patients suffering from idiopathic ICH, TBI and during hydrocephalus therapy [5]. An incorrect PP can therefore increase intra-thoracic pressure via diaphragm elevation, causing impaired blood outflow from the brain leading to increase in ICP (Fig. 1). Hence, the elevated IAP following abdominal compression during PP plays a crucial role during ICP management, particularly in obese patients. Although we agree with the suggestions from Bernon et al. [1] regarding the need to close brain-monitoring in ARDS patients with TBI undergoing PP, we further suggest to include IAP monitoring and to carefully check the patient's position in order to avoid abdominal compression during PP. Further studies should be performed to explain the relationships between changes in IAP and risk of increase in ICP in patients with concomitant ARDS and TBI treated with PP. original author(s) and the source, provide a link to the Creative Commons licence, and indicate if changes were made. The images or other third party material in this article are included in the article's Creative Commons licence, unless indicated otherwise in a credit line to the material. If material is not included in the article's Creative Commons licence and your intended use is not permitted by statutory regulation or exceeds the permitted use, you will need to obtain permission directly from the copyright holder. To view a copy of this licence, visit http://creativecommons.org/licenses/by/4.0/. The Creative Commons Public Domain Dedication waiver (http://creativeco mmons.org/publicdomain/zero/1.0/) applies to the data made available in this article, unless otherwise stated in a credit line to the data. 
a

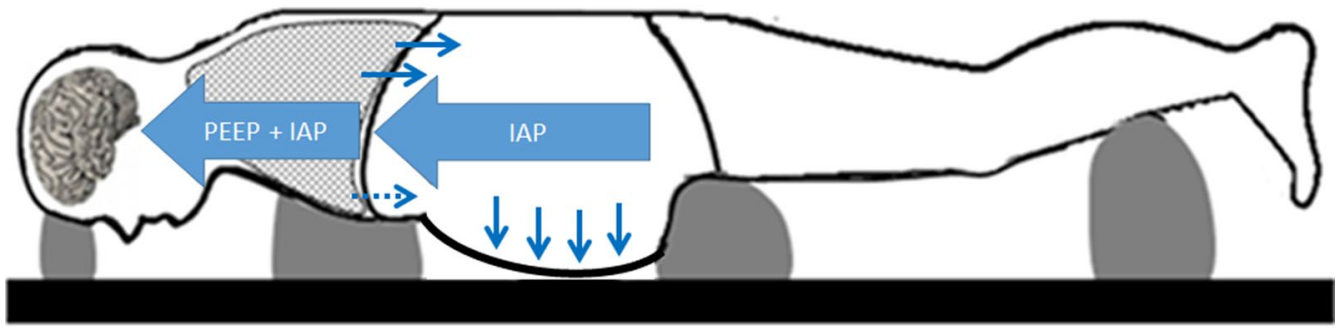

b

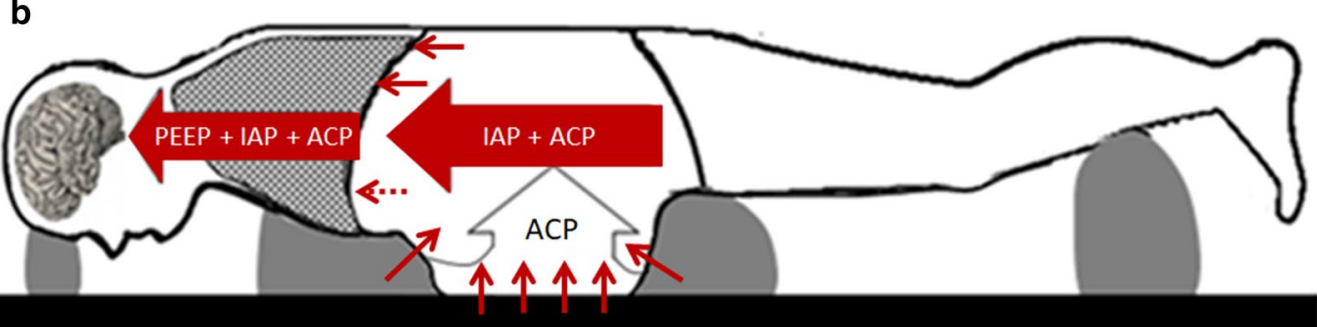

Fig. 1 Diagram illustration correct (a) and incorrect (b) prone positioning in a patient treated for traumatic brain injury complicated with moderate-to-severe acute respiratory distress syndrome (ARDS). Correct positioning with abdominal suspension, so that the abdomen can hang free will not increase IAP during PP. An incorrect positioning on the contrary will increase IAP by a back pressure resulting from compression of the abdomen by the bed and faulty suspension. IAP intra-abdominal pressure, ACP abdominal compression pressure, PEEP positive end-respiratory pressure

\section{Authors' response \\ Prone positioning modalities are essential for good tolerance in patients with acute brain injury \\ Pauline Bernon ${ }^{6}$, Anne-Claire Lukaszewicz ${ }^{6,7}$, Baptiste Balança $a^{6,8^{*}}$ \\ *Correspondence: baptiste.balanca@gmail.com \\ ${ }^{6}$ Hospices Civils de Lyon, Département d'anesthésie réanimation, Hôpital Neurologique Pierre Wertheimer, 59 Boulevard Pinel, 69500 Bron, France. ${ }^{7}$ EA 7426 PI3 (Pathophysiology of Injury-induced Immunosuppression), Hospices Civils de Lyon/Université Claude Bernard Lyon 1/bioMérieux, Hôpital E. Herriot, 5, place d'Arsonval, 69437 Lyon, Cedex 03, France. \\ ${ }^{8}$ U1028, UMR 5292, Lyon Neuroscience Research Center, Bron, France.}

\section{Dear Editor,}

Dabrowski et al. published a letter in the journal about our work reporting data on the safety and efficacy of prone positioning (PP) in patients with acute brain injury and moderate-to-severe acute respiratory distress syndrome (ARDS) [1]. They suggest monitoring intraabdominal pressure (IAP) in addition to brain compliance to evaluate the risk of impaired brain venous return during PP particularly in obese patients. In our cohort, intracranial hypertension ( $\mathrm{ICH}$, intracranial pressureICP $>25 \mathrm{mmHg}$ ) occurred in $14 / 27$ patients $(52 \%)$ leading to discontinue PP in $5 / 27$ patients. Only $7 / 27$ patients (26\%) had a body mass index over $30 \mathrm{~kg} / \mathrm{m}^{2}, 30 \%$ of whom $(n=3)$ had ICH during PP. The number of obese patients at risk of increased IAP was too small to conclude, and we agree with Dabrowski et al. that IAP plays a critical role in venous return changes during PP. The pressure in the right atrium, which drives cerebral blood outflow, is influence by cardiac output, intrathoracic pressure and to some extent by the venous pressure from other organs. PP is expected to improve thoracic compliance and thereby venous return; however, the increase in IAP may hinder this beneficial effect. For instance, during elective spine surgery the only frame that can reduce hemodynamic changes triggered by PP allows the abdomen to hang free [6] thereby preventing IAP elevation. This strategy has also been implemented in the intensive care unit with circular pillow during PP [7]. IAP release may therefore be transmitted to the right atrium and eventually to the brain, thereby improving cerebral outflow. Consequently, monitoring IAP could allow optimizing the positioning of patients with a high central venous pressure. In our opinion, head position remains one major determinant of cerebral blood outflow. It must remain on the axis in order to avoid compression of the jugular veins. The elevation of the head above the heart level is also important and allows to reduce intracranial pressure (ICP) in brain injured patients [8]. We agree that abdominal pressure release and monitoring should be considered during PP, but we would argue to test the tolerance to an obstacle to cerebral blood outflow before PP to identify patient at risk of $\mathrm{IH}$. The evaluation of a protocol that standardize head position and abdomen release is therefore necessary to decrease the risk of $\mathrm{IH}$ 
during PP sessions in patients with acute brain injury and ARDS.

\section{Acknowledgements}

None.

\section{Authors' contributions}

Each authors have made substantial contribution to conception of this paper. WD and CR designed of the work and drafted the manuscript. DSG, RB and MLNGM were involved in references collection, figure preparation and corrected the manuscript. All authors designed the study, drafted the manuscript, read and approved the final version. All authors meet key authorship requirements and agree to be accountable for all aspects of the work in ensuring that questions related to the accuracy are appropriately documented in the literature. All authors read and approved the final manuscript.

\section{Funding}

Not applicable.

\section{Availability of data and materials}

Not applicable.

Ethical approval and consent to participate

Not applicable.

\section{Consent for publication}

Not applicable.

\section{Competing interests}

The authors declare that they have no competing interest.

\section{Author details}

1 Department of Anesthesiology and Intensive Care, Medical University of Lublin, 20-954 Lublin, Poland. ${ }^{2}$ Department of Anaesthesia and Intensive Care, Policlinico San Martino, Genoa, Italy. ${ }^{3}$ Department of Anesthesiology and Intensive Care, Hospital Clinico Universitario de Valencia, University of Valencia, Valencia, Spain. ${ }^{4}$ Department of Electronics and Informatics (ETRO), Faculty of Engineering, Vrije Universiteit Brussel (VUB), Brussels, Belgium. ${ }^{5}$ International Fluid Academy, Lovenjoel, Belgium.

Received: 28 January 2021 Accepted: 10 February 2021

Published online: 07 April 2021

\section{References}

1. Bernon P, Mrozek S, Dupont G, Dailler F, Lukaszewicz AC, Balanca B. Can prone positioning be safe procedure in patients with acute brain injury and moderate-to-severe acute respiratory distress syndrome? Crit Care. 2021;25(1):30. https://doi.org/10.1186/s13054-020-03454-9.

2. Robba C, Poole D, McNett M, Asehnoune K, Bösel J, Bruder N, et al. Mechanical ventilation in patients with acute brain injury: recommendations of the European Society of Intensive Care Medicine consensus. Intensive Care Med. 2020;46(12):2397-410. https://doi.org/10.1007/ s00134-020-06283-0.

3. Picetti E, Pelosi P, Taccone FS, Citerio G, Mancebo J, Robba C et al. VINTIlatory strategies in patients with severe traumatic brain injury: the VENTILO survey of the European Society of Intensive Care Medicind (ESICM). Crit Care. 2020; 24(1): 158. https://doi.org/10.1186/s13054-020-02875-w.

4. Kotlinska-Hasiec E, Dabrowski W, Rzecki Z, Rybojad B, Pilat J, De Keulenaer $B$, et al. Association between intra-abdominal pressure and jugular bulb saturation in critically ill patients. Minerva Anestesiol. 2014;80:785-95.

5. Depauw PRAM, Groen RJM, VanLoon J, Peul WC, Malbrain MLNG, De Waele $\mathrm{J}$. The significance of intra-abdominal pressure in neurosurgery and neurological diseases: a narrative review and conceptual proposal. Acta Neurochir. 2019;161(5):855-64. https://doi.org/10.1007/ s00701-019-03868-7.

6. Dharmavaram S, Jellish WS, Nockels RP, Shea J, Mehmood R, Ghanayem A, et al. Effect of prone positioning systems on hemodynamic and cardiac function during lumbar spine surgery: an echocardiographic study. Spine. 2006;31:1388-93.

7. Gaudry S, Tuffet S, Lukaszewicz A-C, Laplace C, Zucman N, Pocard M, et al. Prone positioning in acute respiratory distress syndrome after abdominal surgery: a multicenter retrospective study. Ann Intensive Care. 2017;7:21.

8. $\mathrm{Ng} \mathrm{l}$, Lim J, Wong HB. Effects of head posture on cerebral hemodynamics: its influences on intracranial pressure, cerebral perfusion pressure, and cerebral oxygenation. Neurosurgery. 2004;54:593-8.

\section{Publisher's Note}

Springer Nature remains neutral with regard to jurisdictional claims in published maps and institutional affiliations.
Ready to submit your research? Choose BMC and benefit from:

- fast, convenient online submission

- thorough peer review by experienced researchers in your field

- rapid publication on acceptance

- support for research data, including large and complex data types

- gold Open Access which fosters wider collaboration and increased citations

- maximum visibility for your research: over $100 \mathrm{M}$ website views per year

At BMC, research is always in progress.

Learn more biomedcentral.com/submissions 